\title{
Common coupled fixed point theorems for weakly compatible mappings in fuzzy metric spaces
}

\author{
Xin-Qi Hu ${ }^{1 *}$, Ming-Xue Zheng ${ }^{1}$, Boško Damjanović ${ }^{2}$ and Xiao-Feng Shao ${ }^{3}$
}

\section{"Correspondence:}

xqhu.math@whu.edu.cn

${ }^{1}$ School of Mathematics and

Statistics, Wuhan University, Wuhan,

430072, P.R. China

Full list of author information is

available at the end of the article

\begin{abstract}
In this paper, we prove a common fixed point theorem for weakly compatible mappings under $\phi$-contractive conditions in fuzzy metric spaces. We also give an example to illustrate the theorem. The result is a genuine generalization of the corresponding result of Hu (Fixed Point Theory Appl. 2011:363716, 2011, doi:10.1155/2011/363716). We also indicate a minor mistake in Hu (Fixed Point Theory Appl. 2011:363716, 2011, doi:10.1155/2011/363716).
\end{abstract}

\section{Introduction}

In 1965, Zadeh [1] introduced the concept of fuzzy sets. Then many authors gave the important contribution to development of the theory of fuzzy sets and applications. George and Veeramani [2,3] gave the concept of a fuzzy metric space and defined a Hausdorff topology on this fuzzy metric space, which have very important applications in quantum particle physics, particularly, in connection with both string and E-infinity theory.

Bhaskar and Lakshmikantham [4], Lakshmikantham and Ćirić [5] discussed the mixed monotone mappings and gave some coupled fixed point theorems, which can be used to discuss the existence and uniqueness of solution for a periodic boundary value problem. Sedghi et al. [6] gave a coupled fixed point theorem for contractions in fuzzy metric spaces, and Jin-xuan Fang [7] gave some common fixed point theorems for compatible and weakly compatible $\phi$-contractions mappings in Menger probabilistic metric spaces. Xin-Qi Hu [8] proved a common fixed point theorem for mappings under $\varphi$-contractive conditions in fuzzy metric spaces. Many authors [9-26] proved fixed point theorems in (intuitionistic) fuzzy metric spaces or probabilistic metric spaces.

In this paper, we give a new coupled fixed point theorem under weaker conditions than in [8] and give an example, which shows that the result is a genuine generalization of the corresponding result in [8].

\section{Preliminaries}

First, we give some definitions.

Definition 2.1 (see [2]) A binary operation $*:[0,1] \times[0,1] \rightarrow[0,1]$ is a continuous $t$-norm if $*$ satisfies the following conditions:

(1) $*$ is commutative and associative,

o 2013 Hu et al: licensee Springer. This is an Open Access article distributed under the terms of the Creative Commons Attribution License (http://creativecommons.org/licenses/by/2.0), which permits unrestricted use, distribution, and reproduction in any medium, provided the original work is properly cited. 
(2) $*$ is continuous,

(3) $a * 1=a$ for all $a \in[0,1]$,

(4) $a * b \leq c * d$ whenever $a \leq c$ and $b \leq d$ for all $a, b, c, d \in[0,1]$.

Definition 2.2 (see [27]) Let $\sup _{0<t<1} \Delta(t, t)=1$. A $t$-norm $\Delta$ is said to be of H-type if the family of functions $\left\{\Delta^{m}(t)\right\}_{m=1}^{\infty}$ is equicontinuous at $t=1$, where

$$
\Delta^{1}(t)=t \Delta t, \quad \Delta^{m+1}(t)=t \Delta\left(\Delta^{m}(t)\right), \quad m=1,2, \ldots, t \in[0,1]
$$

The $t$-norm $\Delta_{M}=$ min is an example of $t$-norm of $\mathrm{H}$-type, but there are some other $t$-norms $\Delta$ of H-type [27].

Obviously, $\Delta$ is a $t$-norm of $\mathrm{H}$-type if and only if for any $\lambda \in(0,1)$, there exists $\delta(\lambda) \in(0,1)$ such that $\Delta^{m}(t)>1-\lambda$ for all $m \in \mathbb{N}$, when $t>1-\delta$.

Definition 2.3 (see [2]) A 3-tuple $(X, M, *)$ is said to be a fuzzy metric space if $X$ is an arbitrary nonempty set, $*$ is a continuous $t$-norm and $M$ is a fuzzy set on $X^{2} \times(0,+\infty)$ satisfying the following conditions for each $x, y, z \in X$ and $t, s>0$,

$(\mathrm{FM}-1) M(x, y, t)>0$,

(FM-2) $M(x, y, t)=1$ if and only if $x=y$,

(FM-3) $M(x, y, t)=M(y, x, t)$,

(FM-4) $M(x, y, t) * M(y, z, s) \leq M(x, z, t+s)$,

$(\mathrm{FM}-5) M(x, y, \cdot):(0, \infty) \rightarrow[0,1]$ is continuous

We shall consider a fuzzy metric space $(X, M, *)$, which satisfies the following condition:

$$
\lim _{t \rightarrow+\infty} M(x, y, t)=1, \quad \forall x, y \in X
$$

Let $(X, M, *)$ be a fuzzy metric space. For $t>0$, the open ball $B(x, r, t)$ with a center $x \in X$ and a radius $0<r<1$ is defined by

$$
B(x, r, t)=\{y \in X: M(x, y, t)>1-r\} .
$$

A subset $A \subset X$ is called open if for each $x \in A$, there exist $t>0$ and $0<r<1$ such that $B(x, r, t) \subset A$. Let $\tau$ denote the family of all open subsets of $X$. Then $\tau$ is called the topology on $X$, induced by the fuzzy metric $M$. This topology is Hausdorff and first countable.

Example 2.4 Let $(X, d)$ be a metric space. Define $t$-norm $a * b=a b$ or $a * b=\min \{a, b\}$ and for all $x, y \in X$ and $t>0, M(x, y, t)=\frac{t}{t+d(x, y)}$. Then $(X, M, *)$ is a fuzzy metric space.

Definition 2.5 (see [2]) Let $(X, M, *)$ be a fuzzy metric space. Then

(1) a sequence $\left\{x_{n}\right\}$ in $X$ is said to be convergent to $x$ (denoted by $\lim _{n \rightarrow \infty} x_{n}=x$ ) if

$$
\lim _{n \rightarrow \infty} M\left(x_{n}, x, t\right)=1
$$

for all $t>0$. 
(2) A sequence $\left\{x_{n}\right\}$ in $X$ is said to be a Cauchy sequence if for any $\varepsilon>0$, there exists $n_{0} \in \mathbb{N}$, such that

$$
M\left(x_{n}, x_{m}, t\right)>1-\varepsilon
$$

for all $t>0$ and $n, m \geq n_{0}$.

(3) A fuzzy metric space $(X, M, *)$ is said to be complete if and only if every Cauchy sequence in $X$ is convergent.

Remark 2.6 (see [9]) Let $(X, M, *)$ be a fuzzy metric space. Then

(1) for all $x, y \in X, M(x, y, \cdot)$ is non-decreasing;

(2) if $x_{n} \rightarrow x, y_{n} \rightarrow y, t_{n} \rightarrow t$, then

$$
\lim _{n \rightarrow \infty} M\left(x_{n}, y_{n}, t_{n}\right)=M(x, y, t)
$$

(3) if $M(x, y, t)>1-r$ for $x, y$ in $X, t>0,0<r<1$, then we can find a $t_{0}, 0<t_{0}<t$ such that $M\left(x, y, t_{0}\right)>1-r$;

(4) for any $r_{1}>r_{2}$, we can find a $r_{3}$ such that $r_{1} * r_{3} \geq r_{2}$, and for any $r_{4}$, we can find a $r_{5}$ such that $r_{5} * r_{5} \geq r_{4}\left(r_{1}, r_{2}, r_{3}, r_{4}, r_{5} \in(0,1)\right)$.

Define $\Phi=\left\{\phi: R^{+} \rightarrow R^{+}\right\}$, where $R^{+}=[0,+\infty)$ and each $\phi \in \Phi$ satisfies the following conditions:

$(\phi-1) \phi$ is non-decreasing,

$(\phi-2) \phi$ is upper semi-continuous from the right,

$(\phi-3) \sum_{n=0}^{\infty} \phi^{n}(t)<+\infty$ for all $t>0$, where $\phi^{n+1}(t)=\phi\left(\phi^{n}(t)\right), n \in \mathbb{N}$.

It is easy to prove that if $\phi \in \Phi$, then $\phi(t)<t$ for all $t>0$.

Lemma 2.7 (see [7]) Let $(X, M, *)$ be a fuzzy metric space, where $*$ is a continuous $t$-norm of H-type. If there exists $\phi \in \Phi$ such that

$$
M(x, y, \phi(t)) \geq M(x, y, t)
$$

for all $t>0$, then $x=y$.

Definition 2.8 (see [4]) An element $(x, y) \in X \times X$ is called a coupled fixed point of the mapping $F: X \times X \rightarrow X$ if

$$
F(x, y)=x, \quad F(y, x)=y
$$

Definition 2.9 (see [5]) An element $(x, y) \in X \times X$ is called a coupled coincidence point of the mappings $F: X \times X \rightarrow X$ and $g: X \rightarrow X$ if

$$
F(x, y)=g(x), \quad F(y, x)=g(y) .
$$


Definition 2.10 (see [5]) An element $(x, y) \in X \times X$ is called a common coupled fixed point of the mappings $F: X \times X \rightarrow X$ and $g: X \rightarrow X$ if

$$
x=F(x, y)=g(x), \quad y=F(y, x)=g(y) .
$$

Definition 2.11 (see [5]) An element $x \in X$ is called a common fixed point of the mappings $F: X \times X \rightarrow X$ and $g: X \rightarrow X$ if

$$
x=g(x)=F(x, x) .
$$

Definition 2.12 (see [8]) The mappings $F: X \times X \rightarrow X$ and $g: X \rightarrow X$ are said to be compatible if

$$
\lim _{n \rightarrow \infty} M\left(g F\left(x_{n}, y_{n}\right), F\left(g\left(x_{n}\right), g\left(y_{n}\right)\right), t\right)=1
$$

and

$$
\lim _{n \rightarrow \infty} M\left(g F\left(y_{n}, x_{n}\right), F\left(g\left(y_{n}\right), g\left(x_{n}\right)\right), t\right)=1
$$

for all $t>0$ whenever $\left\{x_{n}\right\}$ and $\left\{y_{n}\right\}$ are sequences in $X$, such that

$$
\lim _{n \rightarrow \infty} F\left(x_{n}, y_{n}\right)=\lim _{n \rightarrow \infty} g\left(x_{n}\right)=x, \quad \lim _{n \rightarrow \infty} F\left(y_{n}, x_{n}\right)=\lim _{n \rightarrow \infty} g\left(y_{n}\right)=y,
$$

for all $x, y \in X$ are satisfied.

Definition 2.13 (see [20]) The mappings $F: X \times X \rightarrow X$ and $g: X \rightarrow X$ are called weakly compatible mappings if $F(x, y)=g(x), F(y, x)=g(y)$ implies that $g F(x, y)=F(g x, g y)$, $g F(y, x)=F(g y, g x)$ for all $x, y \in X$.

Remark 2.14 It is easy to prove that if $F$ and $g$ are compatible, then they are weakly compatible, but the converse need not be true. See the example in the next section.

\section{Main results}

For simplicity, denote

$$
[M(x, y, t)]^{n}=\underbrace{M(x, y, t) * M(x, y, t) * \cdots * M(x, y, t)}_{n}
$$

for all $n \in \mathbb{N}$.

Xin-Qi Hu [8] proved the following result.

Theorem 3.1 (see [8]) Let $(X, M, *)$ be a complete FM-space, where $*$ is a continuous $t$ norm of H-type satisfying (2.2). Let $F: X \times X \rightarrow X$ and $g: X \rightarrow X$ be two mappings, and there exists $\phi \in \Phi$ such that

$$
M(F(x, y), F(u, v), \phi(t)) \geq M(g(x), g(u), t) * M(g(y), g(v), t)
$$

for all $x, y, u, v \in X, t>0$. 
Suppose that $F(X \times X) \subseteq g(X), g$ is continuous, $F$ and $g$ are compatible. Then there exist $x, y \in X$ such that $x=g(x)=F(x, x)$; that is, $F$ and $g$ have a unique common fixed point in $X$.

Now we give our main result.

Theorem 3.2 Let $(X, M, *)$ be a FM-space, where $*$ is a continuous $t$-norm of H-type satisfying (2.2). Let $F: X \times X \rightarrow X$ and $g: X \rightarrow X$ be two weakly compatible mappings, and there exists $\phi \in \Phi$ satisfying (3.1).

Suppose that $F(X \times X) \subseteq g(X)$ and $F(X \times X)$ or $g(X)$ is complete. Then $F$ and $g$ have $a$ unique common fixed point in $X$.

Proof Let $x_{0}, y_{0} \in X$ be two arbitrary points in $X$. Since $F(X \times X) \subseteq g(X)$, we can choose $x_{1}, y_{1} \in X$ such that $g\left(x_{1}\right)=F\left(x_{0}, y_{0}\right)$ and $g\left(y_{1}\right)=F\left(y_{0}, x_{0}\right)$. Continuing this process, we can construct two sequences $\left\{x_{n}\right\}$ and $\left\{y_{n}\right\}$ in $X$ such that

$$
g\left(x_{n+1}\right)=F\left(x_{n}, y_{n}\right), \quad g\left(y_{n+1}\right)=F\left(y_{n}, x_{n}\right), \quad \text { for all } n \geq 0 .
$$

The proof is divided into 4 steps.

Step 1: We shall prove that $\left\{g x_{n}\right\}$ and $\left\{g y_{n}\right\}$ are Cauchy sequences.

Since $*$ is a $t$-norm of $\mathrm{H}$-type, for any $\lambda>0$, there exists an $\mu>0$ such that

$$
\underbrace{(1-\mu) *(1-\mu) * \cdots *(1-\mu)}_{k} \geq 1-\lambda
$$

for all $k \in \mathbb{N}$.

Since $M(x, y, \cdot)$ is continuous and $\lim _{t \rightarrow+\infty} M(x, y, t)=1$ for all $x, y \in X$, there exists $t_{0}>0$ such that

$$
M\left(g x_{0}, g x_{1}, t_{0}\right) \geq 1-\mu, \quad M\left(g y_{0}, g y_{1}, t_{0}\right) \geq 1-\mu .
$$

On the other hand, since $\phi \in \Phi$, by condition $\left(\phi\right.$-3), we have $\sum_{n=1}^{\infty} \phi^{n}\left(t_{0}\right)<\infty$. Then for any $t>0$, there exists $n_{0} \in \mathbb{N}$ such that

$$
t>\sum_{k=n_{0}}^{\infty} \phi^{k}\left(t_{0}\right) .
$$

From condition (3.1), we have

$$
\begin{aligned}
M\left(g x_{1}, g x_{2}, \phi\left(t_{0}\right)\right) & =M\left(F\left(x_{0}, y_{0}\right), F\left(x_{1}, y_{1}\right), \phi\left(t_{0}\right)\right) \\
& \geq M\left(g x_{0}, g x_{1}, t_{0}\right) * M\left(g y_{0}, g y_{1}, t_{0}\right), \\
M\left(g y_{1}, g y_{2}, \phi\left(t_{0}\right)\right) & =M\left(F\left(y_{0}, x_{0}\right), F\left(y_{1}, x_{1}\right), \phi\left(t_{0}\right)\right) \\
& \geq M\left(g y_{0}, g y_{1}, t_{0}\right) * M\left(g x_{0}, g x_{1}, t_{0}\right) .
\end{aligned}
$$


Similarly, we have

$$
\begin{aligned}
M\left(g x_{2}, g x_{3}, \phi^{2}\left(t_{0}\right)\right) & =M\left(F\left(x_{1}, y_{1}\right), F\left(x_{2}, y_{2}\right), \phi^{2}\left(t_{0}\right)\right) \\
& \geq M\left(g x_{1}, g x_{2}, \phi\left(t_{0}\right)\right) * M\left(g y_{1}, g y_{2}, \phi\left(t_{0}\right)\right) \\
& \geq\left[M\left(g x_{0}, g x_{1}, t_{0}\right)\right]^{2} *\left[M\left(g y_{0}, g y_{1}, t_{0}\right)\right]^{2}, \\
M\left(g y_{2}, g y_{3}, \phi^{2}\left(t_{0}\right)\right) & =M\left(F\left(y_{1}, x_{1}\right), F\left(y_{2}, x_{2}\right), \phi^{2}\left(t_{0}\right)\right) \\
& \geq\left[M\left(g y_{0}, g y_{1}, t_{0}\right)\right]^{2} *\left[M\left(g x_{0}, g x_{1}, t_{0}\right)\right]^{2} .
\end{aligned}
$$

From the inequalities above and by induction, it is easy to prove that

$$
\begin{aligned}
& M\left(g x_{n}, g x_{n+1}, \phi^{n}\left(t_{0}\right)\right) \geq\left[M\left(g x_{0}, g x_{1}, t_{0}\right)\right]^{2^{n-1}} *\left[M\left(g y_{0}, g y_{1}, t_{0}\right)\right]^{2^{n-1}}, \\
& M\left(g y_{n}, g y_{n+1}, \phi^{n}\left(t_{0}\right)\right) \geq\left[M\left(g y_{0}, g y_{1}, t_{0}\right)\right]^{2^{n-1}} *\left[M\left(g x_{0}, g x_{1}, t_{0}\right)\right]^{2^{n-1}} .
\end{aligned}
$$

So, from (3.3) and (3.4), for $m>n \geq n_{0}$, we have

$$
\begin{aligned}
M\left(g x_{n}, g x_{m}, t\right) \geq & M\left(g x_{n}, g x_{m}, \sum_{k=n_{0}}^{\infty} \phi^{k}\left(t_{0}\right)\right) \\
\geq & M\left(g x_{n}, g x_{m}, \sum_{k=n}^{m-1} \phi^{k}\left(t_{0}\right)\right) \\
\geq & M\left(g x_{n}, g x_{n+1}, \phi^{n}\left(t_{0}\right)\right) * M\left(g x_{n+1}, g x_{n+2}, \phi^{n+1}\left(t_{0}\right)\right) * \cdots \\
& * M\left(g x_{m-1}, g x_{m}, \phi^{m-1}\left(t_{0}\right)\right) \\
\geq & {\left[M\left(g y_{0}, g y_{1}, t_{0}\right)\right]^{2^{n-1}} *\left[M\left(g x_{0}, g x_{1}, t_{0}\right)\right]^{2^{n-1}} *\left[M\left(g y_{0}, g y_{1}, t_{0}\right)\right]^{2^{n}} } \\
& *\left[M\left(g x_{0}, g x_{1}, t_{0}\right)\right]^{2^{n}} * \cdots *\left[M\left(g y_{0}, g y_{1}, t_{0}\right)\right]^{2^{m-2}} \\
& *\left[M\left(g x_{0}, g x_{1}, t_{0}\right)\right]^{2^{m-2}} \\
= & {\left[M\left(g y_{0}, g y_{1}, t_{0}\right)\right]^{2^{m-1}-2^{n-1}} *\left[M\left(g x_{0}, g x_{1}, t_{0}\right)\right]^{2^{m-1}-2^{n-1}} } \\
\geq & \underbrace{(1-\mu) *(1-\mu) * \cdots *(1-\mu) \geq 1-\lambda,}_{2^{m}-2^{n}}
\end{aligned}
$$

which implies that

$$
M\left(g x_{n}, g x_{m}, t\right)>1-\lambda
$$

for all $m, n \in \mathbb{N}$ with $m>n \geq n_{0}$ and $t>0$. So $\left\{g\left(x_{n}\right)\right\}$ is a Cauchy sequence.

Similarly, we can prove that $\left\{g\left(y_{n}\right)\right\}$ is also a Cauchy sequence.

Step 2: Now, we prove that $g$ and $F$ have a coupled coincidence point.

Without loss of generality, we can assume that $g(X)$ is complete, then there exist $x, y \in$ $g(X)$, and exist $a, b \in X$ such that

$$
\begin{aligned}
& \lim _{n \rightarrow \infty} g\left(x_{n}\right)=\lim _{n \rightarrow \infty} F\left(x_{n}, y_{n}\right)=g(a)=x, \\
& \lim _{n \rightarrow \infty} g\left(y_{n}\right)=\lim _{n \rightarrow \infty} F\left(y_{n}, x_{n}\right)=g(b)=y .
\end{aligned}
$$


From (3.1), we get

$$
M\left(F\left(x_{n}, y_{n}\right), F(a, b), \phi(t)\right) \geq M\left(g x_{n}, g(a), t\right) * M\left(g y_{n}, g(b), t\right) .
$$

Since $M$ is continuous, taking limit as $n \rightarrow \infty$, we have

$$
M(g(a), F(a, b), \phi(t))=1,
$$

which implies that $F(a, b)=g(a)=x$.

Similarly, we can show that $F(b, a)=g(b)=y$.

Since $F$ and $g$ are weakly compatible, we get that $g F(a, b)=F(g(a), g(b))$ and $g F(b, a)=$ $F(g(b), g(a))$, which implies that $g(x)=F(x, y)$ and $g(y)=F(y, x)$.

Step 3: We prove that $g(x)=y$ and $g(y)=x$.

Since $*$ is a $t$-norm of $\mathrm{H}$-type, for any $\lambda>0$, there exists an $\mu>0$ such that

$$
\underbrace{(1-\mu) *(1-\mu) * \cdots *(1-\mu)}_{k} \geq 1-\lambda
$$

for all $k \in \mathbb{N}$.

Since $M(x, y, \cdot)$ is continuous and $\lim _{t \rightarrow+\infty} M(x, y, t)=1$ for all $x, y \in X$, there exists $t_{0}>0$ such that $M\left(g x, y, t_{0}\right) \geq 1-\mu$ and $M\left(g y, x, t_{0}\right) \geq 1-\mu$.

On the other hand, since $\phi \in \Phi$, by condition $(\phi-3)$, we have $\sum_{n=1}^{\infty} \phi^{n}\left(t_{0}\right)<\infty$. Thus, for any $t>0$, there exists $n_{0} \in \mathbb{N}$ such that $t>\sum_{k=n_{0}}^{\infty} \phi^{k}\left(t_{0}\right)$. Since

$$
\begin{aligned}
M\left(g x, g y_{n+1}, \phi\left(t_{0}\right)\right) & =M\left(F(x, y), F\left(y_{n}, x_{n}\right), \phi\left(t_{0}\right)\right) \\
& \geq M\left(g x, g y_{n}, t_{0}\right) * M\left(g y, g x_{n}, t_{0}\right),
\end{aligned}
$$

letting $n \rightarrow \infty$, we get

$$
M\left(g x, y, \phi\left(t_{0}\right)\right) \geq M\left(g x, y, t_{0}\right) * M\left(g y, x, t_{0}\right) .
$$

Similarly, we can get

$$
M\left(g y, x, \phi\left(t_{0}\right)\right) \geq M\left(g x, y, t_{0}\right) * M\left(g y, x, t_{0}\right) .
$$

From (3.7) and (3.8), we have

$$
M\left(g x, y, \phi\left(t_{0}\right)\right) * M\left(g y, x, \phi\left(t_{0}\right)\right) \geq\left[M\left(g x, y, t_{0}\right)\right]^{2} *\left[M\left(g y, x, t_{0}\right)\right]^{2} .
$$

From this inequality, we can get

$$
\begin{aligned}
M\left(g x, y, \phi^{n}\left(t_{0}\right)\right) * M\left(g y, x, \phi^{n}\left(t_{0}\right)\right) & \geq\left[M\left(g x, y, \phi^{n-1}\left(t_{0}\right)\right)\right]^{2} *\left[M\left(g y, x, \phi^{n-1}\left(t_{0}\right)\right)\right]^{2} \\
& \geq\left[M\left(g x, y, t_{0}\right)\right]^{2^{n}} *\left[M\left(g y, x, t_{0}\right)\right]^{2^{n}}
\end{aligned}
$$


for all $n \in \mathbb{N}$. Since $t>\sum_{k=n_{0}}^{\infty} \phi^{k}\left(t_{0}\right)$, then, we have

$$
\begin{aligned}
M(g x, y, t) * M(g y, x, t) & \geq M\left(g x, y, \sum_{k=n_{0}}^{\infty} \phi^{k}\left(t_{0}\right)\right) * M\left(g y, x, \sum_{k=n_{0}}^{\infty} \phi^{k}\left(t_{0}\right)\right) \\
& \geq M\left(g x, y, \phi^{n_{0}}\left(t_{0}\right)\right) * M\left(g y, x, \phi^{n_{0}}\left(t_{0}\right)\right) \\
& \geq\left[M\left(g x, y, t_{0}\right)\right]^{2^{n_{0}}} *\left[M\left(g y, x, t_{0}\right)\right]^{2^{n_{0}}} \\
& \geq \underbrace{(1-\mu) *(1-\mu) * \cdots *(1-\mu)}_{2^{2 n_{0}}} \geq 1-\lambda .
\end{aligned}
$$

Therefore, for any $\lambda>0$, we have

$$
M(g x, y, t) * M(g y, x, t) \geq 1-\lambda
$$

for all $t>0$. Hence conclude that $g x=y$ and $g y=x$.

Step 4: Now, we prove that $x=y$.

Since $*$ is a $t$-norm of $\mathrm{H}$-type, for any $\lambda>0$, there exists an $\mu>0$ such that

$$
\underbrace{(1-\mu) *(1-\mu) * \cdots *(1-\mu)}_{k} \geq 1-\lambda
$$

for all $k \in \mathbb{N}$.

Since $M(x, y, \cdot)$ is continuous and $\lim _{t \rightarrow+\infty} M(x, y, t)=1$, there exists $t_{0}>0$ such that $M\left(x, y, t_{0}\right) \geq 1-\mu$.

On the other hand, since $\phi \in \Phi$, by condition $(\phi-3)$, we have $\sum_{n=1}^{\infty} \phi^{n}\left(t_{0}\right)<\infty$. Then, for any $t>0$, there exists $n_{0} \in \mathbb{N}$ such that $t>\sum_{k=n_{0}}^{\infty} \phi^{k}\left(t_{0}\right)$.

From (3.1), we have

$$
\begin{aligned}
M\left(g x_{n+1}, g y_{n+1}, \phi\left(t_{0}\right)\right) & =M\left(F\left(x_{n}, y_{n}\right), F\left(y_{n}, x_{n}\right), \phi\left(t_{0}\right)\right) \\
& \geq M\left(g x_{n}, g y_{n}, t_{0}\right) * M\left(g y_{n}, g x_{n}, t_{0}\right) .
\end{aligned}
$$

Letting $n \rightarrow \infty$ yields

$$
M\left(x, y, \phi\left(t_{0}\right)\right) \geq M\left(x, y, t_{0}\right) * M\left(y, x, t_{0}\right) .
$$

Thus, we have

$$
\begin{aligned}
M(x, y, t) & \geq M\left(x, y, \sum_{k=n_{0}}^{\infty} \phi^{k}\left(t_{0}\right)\right) \\
& \geq M\left(x, y, \phi^{n_{0}}\left(t_{0}\right)\right) \\
& \geq\left[M\left(x, y, t_{0}\right)\right]^{2^{n_{0}-1}} *\left[M\left(y, x, t_{0}\right)\right]^{2^{n_{0}-1}} \\
& \geq \underbrace{(1-\mu) *(1-\mu) * \cdots *(1-\mu)}_{2^{2 n_{0}-2}} \geq 1-\lambda,
\end{aligned}
$$

which implies that $x=y$. 
Thus, we proved that $F$ and $g$ have a common fixed point in $X$.

The uniqueness of the fixed point can be easily proved in the same way as above. This completes the proof of Theorem 3.2.

Taking $g=I$ (the identity mapping) in Theorem 3.2, we get the following consequence.

Corollary 3.3 Let $(X, M, *)$ be a FM-space, where $*$ is a continuous $t$-norm of H-type satisfying (2.2). Let $F: X \times X \rightarrow X$, and there exists $\phi \in \Phi$ such that

$$
M(F(x, y), F(u, v), \phi(t)) \geq M(x, u, t) * M(y, v, t)
$$

for all $x, y, u, v \in X, t>0 . F(X)$ is complete.

Then there exist $x \in X$ such that $x=F(x, x)$; that is, $F$ admits a unique fixed point in $X$.

Remark 3.4 Comparing Theorem 3.2 with Theorem 3.1 in [8], we can see that Theorem 3.2 is a genuine generalization of Theorem 3.2.

(1) We only need the completeness of $g(X)$ or $F(X \times X)$.

(2) The continuity of $g$ is relaxed.

(3) The concept of compatible has been replaced by weakly compatible.

Remark 3.5 The Example 3 in [8] is wrong, since the $t$-norm $a * b=a b$ is not the $t$-norm of H-type.

Next, we give an example to support Theorem 3.2.

Example 3.6 Let $X=\left\{0,1, \frac{1}{2}, \frac{1}{3}, \ldots, \frac{1}{n}, \ldots\right\}, *=\min , M(x, y, t)=\frac{t}{|x-y|+t}$, for all $x, y \in X, t>0$. Then $(X, M, *)$ is a fuzzy metric space.

Let $\phi(t)=\frac{t}{2}$. Let $g: X \rightarrow X$ and $F: X \times X \rightarrow X$ be defined as

$$
g(x)=\left\{\begin{array}{lll}
0, & x=0, \\
1, & x=\frac{1}{2 n+1}, \\
\frac{1}{2 n+1}, & x=\frac{1}{2 n},
\end{array} \quad F(x, y)= \begin{cases}\frac{1}{(2 n+1)^{4}}, & (x, y)=\left(\frac{1}{2 n}, \frac{1}{2 n}\right), \\
0, & \text { others. }\end{cases}\right.
$$

Let $x_{n}=y_{n}=\frac{1}{2 n}$. We have $g x_{n}=\frac{1}{2 n+1} \rightarrow 0, F\left(x_{n}, y_{n}\right)=\frac{1}{(2 n+1)^{4}} \rightarrow 0$, but

$$
M\left(F\left(g x_{n}, g y_{n}\right), g F\left(x_{n}, y_{n}\right), t\right)=M(0,1, t) \nrightarrow 0,
$$

so $g$ and $F$ are not compatible. From $F(x, y)=g(x), F(y, x)=g(y)$, we can get $(x, y)=(0,0)$, and we have $g F(0,0)=F(g 0, g 0)$, which implies that $F$ and $g$ are weakly compatible.

The following result is easy to verify

$$
\frac{t}{X+t} \geq \min \left\{\frac{t}{Y+t}, \frac{t}{Z+t}\right\} \quad \Leftrightarrow \quad X \leq \max \{Y, Z\}, \quad \forall X, Y, Z \geq 0, t>0 .
$$

By the definition of $M$ and $\phi$ and the result above, we can get that inequality (3.1)

$$
M(F(x, y), F(u, v), \phi(t)) \geq M(g(x), g(u), t) * M(g(y), g(v), t)
$$


is equivalent to the following

$$
2|F(x, y)-F(u, v)| \leq \max \{|g(x)-g(u)|,|g(y)-g(v)|\} .
$$

Now, we verify inequality (3.11). Let $A=\left\{\frac{1}{2 n}, n \in \mathbb{N}\right\}, B=X-A$. By the symmetry and without loss of generality, $(x, y),(u, v)$ have 6 possibilities.

Case 1: $(x, y) \in B \times B,(u, v) \in B \times B$. It is obvious that (3.11) holds.

Case 2: $(x, y) \in B \times B,(u, v) \in B \times A$. It is obvious that (3.11) holds.

Case 3: $(x, y) \in B \times B,(u, v) \in A \times A$. If $u \neq v$, (3.11) holds. If $u=v$, let $u=v=\frac{1}{2 n}$, then

$$
2|F(x, y)-F(u, v)|=\frac{2}{(2 n+1)^{4}}, \quad \max \{|g(x)-g(u)|,|g(y)-g(v)|\}=\frac{2 n}{2 n+1},
$$

which implies that (3.11) holds.

Case 4: $(x, y) \in B \times A,(u, v) \in B \times A$. It is obvious that (3.11) holds.

Case 5: $(x, y) \in B \times A,(u, v) \in A \times A$. If $u \neq v$, (3.11) holds. If $u=v$, let $x \in B, y=\frac{1}{2 j}$, $u=v=\frac{1}{2 n}$, then

$$
\begin{aligned}
& 2|F(x, y)-F(u, v)|=\frac{2}{(2 n+1)^{4}}, \\
& \max \{|g(x)-g(u)|,|g(y)-g(v)|\}=\max \left\{\frac{1}{2 n+1},\left|\frac{1}{2 j+1}-\frac{1}{2 n+1}\right|\right\},
\end{aligned}
$$

or

$$
\max \{|g(x)-g(u)|,|g(y)-g(v)|\}=\max \left\{\frac{2 n}{2 n+1},\left|\frac{1}{2 j+1}-\frac{1}{2 n+1}\right|\right\},
$$

(3.11) holds.

Case 6: $(x, y) \in A \times A,(u, v) \in A \times A$.

If $x \neq y, u \neq v$, (3.11) holds.

If $x \neq y, u=v$, let $x=\frac{1}{2 i}, y=\frac{1}{2 j}, i \neq j, u=v=\frac{1}{2 n}$. Then

$$
\begin{aligned}
& 2|F(x, y)-F(u, v)|=\frac{2}{(2 n+1)^{4}}, \\
& \max \{|g(x)-g(u)|,|g(y)-g(v)|\}=\max \left\{\left|\frac{1}{2 i+1}-\frac{1}{2 n+1}\right|,\left|\frac{1}{2 j+1}-\frac{1}{2 n+1}\right|\right\},
\end{aligned}
$$

(3.11) holds.

$$
\begin{aligned}
& \text { If } x=y, u=v \text {, let } x=y=\frac{1}{2 i}, u=v=\frac{1}{2 n} \text {. Then } \\
& \quad 2|F(x, y)-F(u, v)|=2\left|\frac{1}{(2 i+1)^{4}}-\frac{1}{(2 n+1)^{4}}\right|, \\
& \quad \max \{|g(x)-g(u)|,|g(y)-g(v)|\}=\left|\frac{1}{2 i+1}-\frac{1}{2 n+1}\right|,
\end{aligned}
$$

(3.11) holds.

Then all the conditions in Theorem 3.2 are satisfied, and 0 is the unique common fixed point of $g$ and $F$. 


\section{Competing interests}

The authors declare that they have no competing interests.

\section{Authors' contributions}

All authors read and approved the final manuscript.

\section{Author details}

${ }^{1}$ School of Mathematics and Statistics, Wuhan University, Wuhan, 430072, P.R. China. ${ }^{2}$ Faculty of Agriculture, University of Belgrade, Nemanjina 6, Belgrade, Serbia. ${ }^{3}$ The General Course Department of Huanggang Polytechnic College, Huanggang, Hubei 438002, P.R. China.

\section{Acknowledgements}

This work of Xin-qi Hu was supported by the National Natural Science Foundation of China (under grant No. 71171150). The research of B. Damjanović was supported by Grant No. 174025 of the Ministry of Education, Science and Technological Development of the Republic of Serbia.

Received: 1 March 2013 Accepted: 1 August 2013 Published: 19 August 2013

\section{References}

1. Zadeh, LA: Fuzzy sets. Inf. Control 8, 338-353 (1965)

2. George, A, Veeramani, P: On some results in fuzzy metric spaces. Fuzzy Sets Syst. 64, 395-399 (1994)

3. George, A, Veeramani, P: On some results of analysis for fuzzy metric spaces. Fuzzy Sets Syst. 90, 365-368 (1997)

4. Bhaskar, TG, Lakshmikantham, V: Fixed point theorems in partially ordered metric spaces and applications. Nonlinear Anal. TMA 65, 1379-1393 (2006)

5. Lakshmikantham, V, Ćirić, LjB: Coupled fixed point theorems for nonlinear contractions in partially ordered metric space. Nonlinear Anal. TMA 70, 4341-4349 (2009)

6. Sedghi, S, Altun, I, Shobe, N: Coupled fixed point theorems for contractions in fuzzy metric spaces. Nonlinear Anal. TMA 72, 1298-1304 (2010)

7. Fang, J-X: Common fixed point theorems of compatible and weakly compatible maps in Menger spaces. Nonlinear Anal. TMA 71, 1833-1843 (2009)

8. Hu, X-Q: Common coupled fixed point theorems for contractive mappings in fuzzy metric spaces. Fixed Point Theory Appl. 2011, Article ID 363716 (2011). doi:10.1155/2011/363716

9. Grabiec, M: Fixed points in fuzzy metric spaces. Fuzzy Sets Syst. 27, 385-398 (1988)

10. Ćirić, LjB, Miheț, D, Saadati, R: Monotone generalized contractions in partially ordered probabilistic metric spaces. Topol. Appl. 156(17), 2838-2844 (2009)

11. O'Regan, D, Saadati, R: Nonlinear contraction theorems in probabilistic spaces. Appl. Math. Comput. 195(1), 86-93 (2008)

12. Jain, $S$, Jain, $S$, Bahadur Jain, L: Compatibility of type $(P)$ in modified intuitionistic fuzzy metric space. J. Nonlinear Sci. Appl. 3(2), 96-109 (2010)

13. Ćirić, Lj, Lakshmikantham, V: Coupled random fixed point theorems for nonlinear contractions in partially ordered metric spaces. Stoch. Anal. Appl. 27(6), 1246-1259 (2009)

14. Ćirić, Lj, Cakić, N, Rajović, M, Ume, JS: Monotone generalized nonlinear contractions in partially ordered metric spaces. Fixed Point Theory Appl. 2008, Article ID 131294 (2008)

15. Aliouche, A, Merghadi, F, Djoudi, A: A related fixed point theorem in two fuzzy metric spaces. J. Nonlinear Sci. Appl. 2(1), 19-24 (2009)

16. Ćirić, Lj: Common fixed point theorems for a family of non-self mappings in convex metric spaces. Nonlinear Anal. 71(5-6), 1662-1669 (2009)

17. Rao, KPR, Aliouche, A, Babu, GR: Related fixed point theorems in fuzzy metric spaces. J. Nonlinear Sci. Appl. 1(3), 194-202 (2008)

18. Ćirić, L, Cakić, N: On Common fixed point theorems for non-self hybrid mappings in convex metric spaces. Appl. Math. Comput. 208(1), 90-97 (2009)

19. Ćirić, L: Some new results for Banach contractions and Edelstein contractive mappings on fuzzy metric spaces. Chaos Solitons Fractals 42, 146-154 (2009)

20. Abbas, M, Ali Khan, M, Radenovic, S: Common coupled fixed point theorems in cone metric spaces for w-compatible mappings. Appl. Math. Comput. 217, 195-202 (2010)

21. Shakeri, S, Ćirić, Lj, Saadati, R: Common fixed point theorem in partially ordered L-fuzzy metric spaces. Fixed Point Theory Appl. 2010, Article ID 125082 (2010). doi:10.1155/2010/125082

22. Ćirić, Lj, Samet, B, Vetro, C: Common fixed point theorems for families of occasionally weakly compatible mappings. Math. Comput. Model. 53(5-6), 631-636 (2011)

23. Ćirić, Lj, Abbas, M, Saadati, R, Hussain, N: Common fixed points of almost generalized contractive mappings in ordered metric spaces. Appl. Math. Comput. 53(9-10), 1737-1741 (2011)

24. Ćirić, L, Abbas, M, Damjanović, B, Saadati, R: Common fuzzy fixed point theorems in ordered metric spaces. Math. Comput. Model. (2010). doi:10.1016/j.mcm.2010.12.050

25. Djoric, D: Nonlinear coupled coincidence and coupled fixed point theorems for not necessary commutative contractive mappings in partially ordered probabilistic metric spaces. Appl. Math. Comput. 219, 5926-5935 (2013)

26. Kamran, T, Cakić, NP: Hybrid tangential property and coincidence point theorems. Fixed Point Theory 9, 487-496 (2008)

27. Hadžić, O, Pap, E: Fixed Point Theory in Probabilistic Metric Spaces. Kluwer Academic, Dordrecht (2001)

doi:10.1186/1687-1812-2013-220

Cite this article as: Hu et al.: Common coupled fixed point theorems for weakly compatible mappings in fuzzy metric spaces. Fixed Point Theory and Applications 2013 2013:220. 